\title{
The First International Conference in Image Management and Communication in Patient Care: Implementation and Impact
}

\author{
Washington, DC, June 4-8, 1989
}

\author{
Seong K. Mun, Melvyn Greberman, and Bruce P. Majors
}

$\mathbf{T}$ HE MANAGEMENT of the vast amount of medical images and information generated in contemporary clinical services is a growing problem. Solutions to the problem increasingly require the use of advanced computerbased technologies in data storage, image display and communication, and human engineering. The progress of individual technologies has been rapid. However, system integration and user acceptance have been slow in coming. As experience accumulates in the clinical application of image management and communication systems (IMACS), a critical assessment of their role in patient care and of their professional and economic impact is useful in developing the future strategies for scientists, users, and manufacturers.

The First International Conference on IMAC will gather together hundreds of clinicians, scientists, engineers, administrators, and policy makers in Washington, DC from June 4-8, 1989. The conference will present leaders in the rapidly growing field of digital imaging from many countries; they will review topics beyond technology and address issues of implementation and the impact of IMAC technology in patient care. Representatives from academia, industry, professional organizations, and government collaborated during the past 2 years to organize this meeting on a wide range of topics in the implementation of IMAC technology and its implications for the clinical environment, technical development, and health services planning. A broad range of interests and the need for support from academia, industry, and user groups were considered in formulating and organizing this unique conference.

With the assistance of numerous colleagues from North America, Japan, and Europe, Seong K. Mun, PhD (Georgetown University Hospital) and Melvyn Greberman, MD, MPH (Center for Devices and Radiological Health, FDA) are the co-chairmen of the organizing committee; William R. Hendee, PhD (AMA) and Roger
Shannon, MD (Veterans Administration) are the co-chairmen of the program committee.

The impact of IMACS extends beyond radiology, as digital imaging technology is becoming increasingly important in radiation medicine, cardiology, neurosurgery, gastroenterology, ophthalmology, neurology, pathology, orthopedics, plastic (reconstructive) surgery, and dentistry. In addition, medical educators and medical information organizations are planning to exploit advanced digital imaging and communication technologies to improve the quality of medical education and the dissemination of medical knowledge.

The plenary sessions in the IMAC program have been organized in a format different from that of the traditional "lecture" style. In each session the first speaker will present an overview and the following three speakers will address specific topics in depth. Following the talks, a discussion leader will conduct a 40-minute question and answer session to promote discussion among the participants. The discussion sessions will be recorded and summaries will be published in the proceedings. The main plenary program is closely coordinated with poster sessions, a tutorial, workshops, and special sessions.

Poster sessions will be held during the twohour lunch periods. Lunch can be purchased in the poster room. This session is designed to promote individualized discussions. The tutorial, which will cover basics of the IMAC concept, will be conducted by an international faculty using supplementary class materials. Early-bird workshops consist of four parallel morning tracks on technical issues that are critical for IMAC. A

From the Department of Radiology, Georgetown University Hospital, Washington, DC, and the Center for Devices and Radiological Health, Food and Drug Administration, Rockville, $M D$.

Address reprint requests to Seong K. Mun, PhD, Department of Radiology, Georgetown University Hospital, 3800 Reservoir Rd, NW, Washington, DC 20007.

(1) 1989 by W.B. Saunders Company.

0897-1889/89/0202-0002\$03.00/0 
significant part of these workshops is the military track. The role of digital imaging and IMAC technology is growing rapidly in the military environment. A number of leaders from the military medical community will provide indepth reviews of the military issues. Workshops are 90-minute sessions that allow ample time for substantive and comprehensive coverage of topics.

Two special sessions are planned for the late afternoon. The ACR-NEMA session will review the progress of ACR-NEMA standards. An industrial panel will discuss the interaction of industry and users in fostering the smooth growth of IMAC technology.

The conference program with discussion topics and invited speakers is summarized in the following section.

Sunday Tutorial: Overview of Basic

IMAC Concepts

Clinical Chairman: R.M. Osteaux, MD, Director of PRIMIS, Belgium

Technical Chairman: B.G. Thompson, Department of Radiology, University of North Carolina, USA

"Technology Overview": Kiyonari Inamura, PhD, Osaka University, Japan

"Clinical Overview": Alan Rowberg, MD, Department of Radiology, University of Washington, USA

"Image Quality": Robert Wagner, PhD, CDRH, USA

"Radiology Information Systems and PACS": Otto Rienhoff, MD, Philipps University Marburg, Germany

"Administrative and Operations": Harold Benson, Department of Radiology, Georgetown University Hospital, USA

Monday AM Session: Scope and Challenges of IMAC in Patient Care: International

Perspectives

Session Chairman: Melvyn Greberman, MD, Center for Devices and Radiological Health, FDA, USA

"European Perspective": Harold Glass, PhD, NW Thames Regional Health Authority, UK

"Japanese Perspective": Masayoshi Akisada, MD, Department of Radiology, The Univer- sity of Tsukuba, Japan

"American Perspective": Roger A. Bauman, MD, Department of Radiology, Massachusetts General Hospital, USA

Discussion Leader: Gerald P. Hanson, DrPH, Chief of Radiation Medicine, World Health Organization, Switzerland

Session Editor: Robert Noordveld, MD, Department of Radiology, University Hospital Leiden, The Netherlands

Monday PM Session: Role of Image-based

Information in Patient Care: Problem Definition

Session Chairman: Josef Lissner, MD, Department of Radiology, University of Munich, Germany

"Primary Care Physician": Mark Braunstein, MD, National Data Corp, USA

"Patient and Medical Records": Albert Bakker, PhD, BAZIS, The Netherlands

"Radiology": Roger Shannon, MD, Radiology Service, Veterans Administration, USA

"Pathology and Laboratory Medicine": Takashi Takahashi, PhD, Department of Medical Informatics, University Medical Center, Japan

Discussion Leader: Atsuko Heshiki, MD, Saitama Medical School, Japan

Session Editor: Diego Bravar, PhD, Department of Medical Instrumentation, National Health Service, Italy

Tuesday AM Session: Approaches to Improved Systems: Current Efforts and Possible Solutions

Chairman: Ludovico Dalla-Palma, MD, Department of Radiology, University of Trieste, Italy

"Patient Medical Records": Shigeto Ikeda, MD, National Cancer Institute, Japan

"Radiology": Goro Irie, MD, Department of Radiology, Hokkaido University, Japan

"Pathology and Laboratory Medicine": Ronald S. Weinstein, MD, Department of Pathology, Rush-Presbyterian St Luke's Hospital, USA

"Dissemination of Medical Information": Michael Ackerman, PhD, National Library of Medicine, USA

Discussion Leader: R. Gilbert Jost, MD, Mallinckrodt Institute of Radiology, USA

Session Editor: Reid E. Kellogg, PhD, DuPont R\&D, Wilmington, USA 
Tuesday PM Session: Technical Barriers to

Network Development and Information

Exchange

Session Chairman: J.M. Scarabin, Université de Rennes, France

"System Integration": John Giunta, AT \& T Medical Systems, USA

"Workstations": John Perry, Gamma Sonics, USA

"Computed Radiography": Hisatoyo Kato, Fuji Film, Miyanodai R \&D, Japan

"Data Storage and Database": H.K. Huang, DSc, Department of Radiological Sciences, UCLA, USA

"Communication and Network": Heinz Lemke, PhD, Technical University of Berlin, Germany

Discussion Leader: William R. Nugent, Automated Systems Office, Library of Congress, USA

Session Editor: Peter Wells, PhD, Bristol General Hospital, UK

Wednesday AM Session: Assuring the Quality of Care

Chairman: Sadayuki Sakuma, MD, Nagoya University Hospital, Japan

Image and Data Quality": Kunio Doi, PhD, Department of Radiology, University of Chicago, USA

"Role of Clinician": Robert A. Greenes, MD, $\mathrm{PhD}$, Department of Radiology, Brigham and Women's Hospital, USA

"Role of Industry": Ronald B. Schilling, PhD, Toshiba Medical Systems, USA

"Role of Government": Harvey Rudolph, PhD, Center for Devices and Radiological Health, FDA, USA

Discussion Leader: Joseph S. Arcarese, Center for Devices and Radiological Health, FDA, USA

Session Editor: Paul Algra, MD, University Hospital Leiden, The Netherlands

Wednesday PM Session: Evaluation of IMAC Technologies

Chairman: Edward V. Staab, MD, Department of Radiology, University of Florida, USA

"Pitfalls in Evaluation": Charles D. Flagle, Dr Eng, Department of Health Policy and Management, The Johns Hopkins University, USA
"Physician Acceptance": Tomoho Maeda, MD, Department of Radiology, Kochi Medical School, Japan

"Organizational Impact": Ronald Arenson, MD, Department of Radiology, University of Pennsylvania, USA

"Cost and Economic Analysis": Robert Hindel, PhD, Advanced Planning, Philips Medical Systems, USA

Discussion Leader: Silas Olsson, The Swedish Planning and Rationalization Institute of The Health and Social Services, Sweden

Session Editor: Bernard Crowe, Health Technology Unit, Australian Institute of Health, Australia

Thursday AM Session: The Future: What Might Happen Next?

Chairman: Larry P. Elliott, MD, Department of Radiology, Georgetown University Hospital, USA

"Technical Perspective": Tetsuo Okabe, MSc, Chief Engineer, Hitachi Medical Systems, Japan

"Implementation": Bart M. ter Haar Romeny, PhD, Department of Radiology, University Hospital Utrecht, The Netherlands

Summation Speaker: William Hendee, PhD, American Medical Association, USA

Session Editor: Steve Horii, MD, Department of Radiology, Georgetown University Hospital, USA

\section{SPECIALTY EARLY-BIRD WORKSHOPS}

Track A: Technology

Chairman: Yongmin Kim, PhD, Department of Electrical Engineering, University of Washington, USA

"CRT Display": Tei Iki, Sony Precision Graphics, USA

"Image Processing Devices": Ken L. Macrae, $\mathrm{PhD}$, MD, Sun Microsystems, USA

"Image Quality: System Design and Evaluation": George Seeley, PhD, University of Arizona, USA

Track B: Evaluation

Chairman: Yoshihisa Nakano, MD, Department of Radiology, Kyoto University Medical Center, Japan 
"Technology Assessment": Gerhard W. Brauer, ACE, School of Medical Information Science, University of Victoria, Canada

"Cost and Economic Analysis": Denise M. Parrish, Department of Radiology, University of North Carolina, USA

"Clinical Acceptance": Hiroshi Nishitani, MD, Department of Radiology, Tokushima University, Japan

\section{Track C: Application}

Chairman: Vicnezo Raffaelli, PhD, Consiglio Nazionale Delle Richerche, Italy

"Dental Imaging" Richard L. Webber, DDS, $\mathrm{PhD}$, University of Alabama, USA; Urs E. Ruttimann, PhD, NIDR, USA

"Space Communications": E. Lee Bryan, Vortech Data Inc, USA

"Radiation Therapy Applications": Ei-Ichi Takenaka, MD, Department of Radiology, Japan National Defense Medical College, Japan

\section{Track D: New Technologies}

Chairman: Mitate Matsui, The Konica Corporation, Japan

"Advances in Communication and Networking": Raymond F. Albers, Bell Atlantic, USA

"Data Cards": Nagaaki Ohyama, PhD, Tokyo Institute Technology, Japan

"Speech Recognition": Joseph Gitlin, DPH, Radiology Information System Consortium, USA

Track E: Military Applications

Monday: "Medical Digital Imaging Within the Defense Medical Establishment"

Tuesday: "Medical Digital Imaging for the Battlefield"

Wednesday: "Medical Digital Imaging in Military Fixed Medical Facilities"

Thursday: "Strategic Approaches for Medical Digital Imaging with the Defense Medical Establishment"
After hours, Washington, DC, will present visitors with a surfeit of interesting leisure-time activities. The Sheraton Washington Hotel, the site of the conference, is the largest hotel/ meeting complex in the nation's capital, near Embassy Row, the National Zoo, the National Cathedral, Rock Creek Park, and other cultural and historic locations and recreational facilities. The city's plentiful taxis and its modern subway system make accessible such sites as the US Capitol, the Washington Monument, the Smithsonian Institution, the Kennedy Center for the Performing Arts, the National Museum of Art, and many other theaters and museums, as well as the area's restaurants, which represent a great diversity of international cuisines.

Future IMAC conferences will be hosted by different countries on a rotational basis every 2 years to ensure the international focus of the conference and facilitate the opportunity to visit operational IMAC sites in different parts of the world. IMAC ' 91 will be hosted by Japan, and plans are underway for IMAC ' 93 to be held in Europe.

The response from the early announcement has been very positive. A large turnout is expected. The conference is expected to be a significant event, bringing many experts and future participants together and establishing the future direction of IMAC technology. Readers are encouraged to participate.

George Washington University Medical Center has arranged for conference participants to receive up to 28 hours of CME in category 1 credit toward the AMA's Physician Recognition Award. Registration (prior to May 12) is $\$ 250$ for members of sponsoring organizations and $\$ 275$ for nonmembers. Anyone interested in receiving program and registration information should contact: Secretariat IMAC '89, Office of Continuing Medical Education, George Washington University, $2300 \mathrm{~K}$ Street, NW, Washington, DC 20037, USA; telephone, (202) 994. 4285; FAX, (202) 994-1791. 